Article

\title{
Diurnal Characteristics of Gravity Waves over the Tibetan Plateau in 2015 Summer Using 10-km Downscaled Simulations from WRF-EnKF Regional Reanalysis
}

\author{
Tingting Qian ${ }^{1,2, *}$, Fuqing Zhang ${ }^{3}$, Junhong Wei ${ }^{4,5, *} \mathbb{C}$, Jie $\mathrm{He}^{6}\left(\mathbb{D}\right.$ and Yinghui $\mathrm{Lu}^{3}$ \\ 1 State Key Laboratory of Severe Weather, Chinese Academy of Meteorological Sciences, Beijing 100081, China \\ 2 Institute of Tibetan Plateau and Polar Meteorology, Chinese Academy of Meteorological Sciences, \\ Beijing 100081, China \\ 3 Department of Meteorology and Atmospheric Science, and Center for Advanced Data Assimilation and \\ Predictability Techniques, The Pennsylvania State University, University Park, PA 16802, USA; \\ yinghuilu123@gmail.com \\ 4 School of Atmospheric Sciences, and Guangdong Province Key Laboratory for Climate Change and Natural \\ Disaster Studies, Sun Yat-sen University, Guangzhou 510275, China \\ 5 Southern Marine Science and Engineering Guangdong Laboratory (Zhuhai), Zhuhai 519082, China \\ 6 Collaborative Innovation Center on Forecast and Evaluation of Meteorological Disasters, Key Laboratory of \\ Meteorological Disaster, Nanjing University of Information Science and Technology, Nanjing 210044, China; \\ tyfcwgl@163.com \\ * Correspondence: qiantt@cma.cn (T.Q.); weijunh@mail.sysu.edu.cn (J.W.)
}

Received: 27 April 2020; Accepted: 8 June 2020; Published: 14 June 2020

check for updates

\begin{abstract}
Diurnal variations of gravity waves over the Tibetan Plateau (TP) in summer 2015 were investigated based on high-resolution downscaled simulations from WRF-EnKF (Weather Research and Forecasting model and an ensemble Kalman filter) regional reanalysis data with particular emphasis on wave source, wave momentum fluxes and wave energies. Strong diurnal precipitations, which mainly happen along the south slope of the TP, tend to excite upward-propagating gravity waves. The spatial and temporal distributions of the momentum fluxes of small-scale (10-200 km) and meso-scale (200-500 km) gravity waves agree well with the diurnal precipitation distributions. The power spectra of momentum fluxes also show that the small- and meso-scale atmospheric processes become important during the period of the strongest rainfall. Eastward momentum fluxes and northward momentum fluxes are dominant. Wave energies are described in terms of kinetic energy $(\mathrm{KE})$, potential energy (PE) and vertical fluctuation energy (VE). The diurnal variation and spatial distribution of VE in the lower stratosphere correspond to the diurnal rainfall in the troposphere.
\end{abstract}

Keywords: gravity wave; diurnal variation; momentum flux; wave energies

\section{Introduction}

Gravity wave is an important phenomenon which interacts with a wide variety of atmospheric processes at almost all scales [1,2]. It can transfer energy excited by small- and meso-scale atmospheric processes in the troposphere to large-scale circulations above the upper troposphere [1,3-10] and modifies the corresponding climate structures [11,12]. Gravity wave sources can include topography [13,14], convection [15-17], temperature gradient [18-22], and wind gradient [23-29]. The Tibetan Plateau (TP), which is the highest plateau in Asia, is an important source of mountain waves. The TP is also an important place of convective gravity waves, as active precipitations usually occur there in summer $[30,31]$. Since gravity waves generated over the TP have substantial effects on 
the regional weather and climate, it is an important subject to explore the associated wave sources and features.

There have been numerous studies of gravity waves based on different approaches-theoretical calculations [2,32-34], observations [7,10,35-40], and numerical simulations [15,17,41-43], to name only a few. However, due to the steep terrain and the lack of high-density observations over the TP, few diurnal features of gravity waves have been documented there. Geller et al. [42] compared gravity wave momentum fluxes among observations, high-resolution climate models (horizontal resolution ranges from $0.23^{\circ}$ to $0.5625^{\circ}$ ), and low-resolution climate models (horizontal resolution ranges from $1.25^{\circ}$ to $2.5^{\circ}$ ). Focused on the TP region, from global gravity wave momentum flux at upper levels for July 2006, high-resolution model results agree with the observations, while coarse-resolution climate model results deviate largely from the observations, which indicate that high-resolution simulations can provide reasonable gravity wave momentum flux distributions to a certain extent. Given that the observations available over the TP are inadequate and few diurnal features of gravity waves over the $\mathrm{TP}$ are documented with high-resolution simulation in the medium term (a 3-month period), it is a reasonable choice to use regional high-resolution forecast models when investigating regional features of gravity waves in summer.

In the current study, the gravity wave features over the TP, i.e., momentum fluxes and wave energies, are investigated using 12-h WRF-EnKF (Weather Research and Forecasting model and an ensemble Kalman filter) forecast results, with 10-km horizontal grid spacing. The goal of this study is to explore wave source, temporal and spatial distribution of the gravity wave momentum fluxes, and wave energies over the TP region. Section 2 describes the 12-h forecast results used in this study. The background fields are exhibited in Section 3. Gravity wave momentum fluxes over the TP and possible wave sources are discussed in Section 4. Gravity wave energy distributions are explored in Section 5. Discussion and the conclusion are presented in Section 6.

\section{Data Description}

\subsection{Data from Ensemble-Based Downscaled Simulation}

The data used in this study are $10 \mathrm{~km}$-grid spacing and $12 \mathrm{~h}$ forecast results from downscaled (improved-resolution) simulations driven by WRF-EnKF reanalysis produced in He et al. [44]. The initial conditions and boundary conditions are obtained from the WRF-EnKF reanalysis data. The forecast model is the Weather Research and Forecasting model developed by UCAR (i.e., WRF model [45]). The previous gravity wave study $[17,28]$ suggests a $10-\mathrm{km}$ resolution can resolve not all but most of the small- and medium-scale waves. It has been verified that the simulated gravity wave spectrum is fairly insensitive to the physics parameterization choices used in the WRF [46]. In addition, since He et al. [44] proved that precipitation simulation performed well for this data, we only list the final choice of physics parameterization used for the current data below. The physical schemes include the WRF double-moment 6-class microphysics scheme, the longwave radiation scheme of the rapid radiative transfer model, the new Goddard shortwave radiation scheme, the Monin-Obukhov similarity surface-layer scheme, the Noah land surface model, and the Yonsei State University boundary layer scheme. According to previous study on regional simulation at $\sim 10 \mathrm{~km}$ resolution [47], no cumulus parameterization scheme can better forecast rainfall processes over Tibetan Plateau [44,47]. More details of the experiment design and physical scheme can be found in He et al. [44].

The data covers a 3-month period from 1 June to 31 August 2015, with two domains over the Tibetan Plateau region (Figure 1 in He et al. [44]). The simulations of domain 1 are coarser, 30-km simulations. The simulations of domain 2, with 10-km grid spacing, employed in the current study are downscaled from the $30-\mathrm{km}$ grid spacing simulations of domain 1 . Domain 2 has a horizontal extent of $313 \times 178$ grid points and 60 vertical levels. The vertical grid spacing is stretched with surface grid spacing $\Delta \mathrm{z} \approx 58 \mathrm{~m}$ and upper grid spacing $\Delta \mathrm{z} \approx 550 \mathrm{~m}$. The model top is set to be $10 \mathrm{hPa}(\sim 31 \mathrm{~km})$. The upper damping layer is imposed for the upper $7 \mathrm{~km}$ with a w-Rayleigh damping 
condition applied [48]. This has weaker damping effects on the vertically propagating gravity wave over 17-24 km (defined as the lower stratosphere and upper troposphere).

(a)

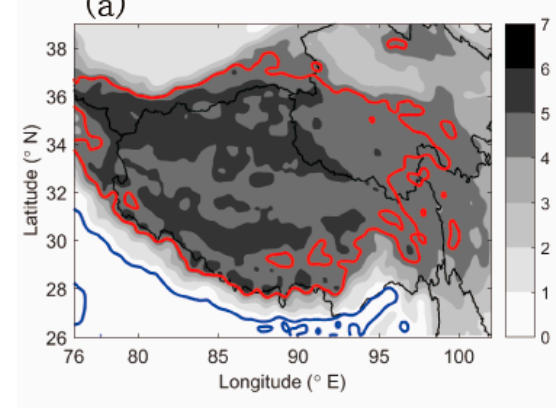

(b) 3-month average

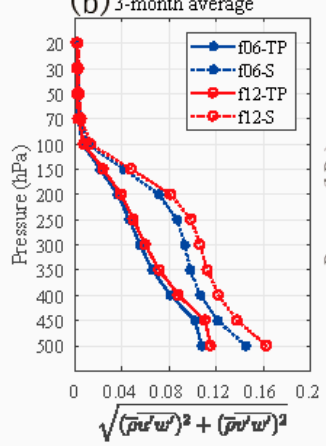

(c) 3-month average

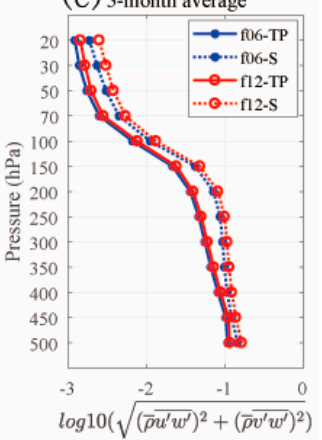

Figure 1. (a) Terrain height (unit: km; shading). The thin black lines are the province border. The red line represents the topography height at $4.5 \mathrm{~km}$. The blue line represents the topography height at $0.3 \mathrm{~km}$. (b) Area-averaged and 3-month-averaged horizontal momentum fluxes per unit volume (unit: Pa) and (c) common logarithm (base 10) of area-averaged and 3-month-averaged horizontal momentum fluxes per unit volume (unit: Pa) over the main TP (solid lines) and the south slope of the TP (dotted lines) from 6-h forecast results (blue lines) and 12-h forecast results (red lines). Legends in $(\mathbf{b}, \mathbf{c})$ are abbreviations of the simulation information. For example, f06 (12) refers to the 6(12)-h forecast. TP refers to the main TP region and S refers to the south slope of the TP.

The terrain height in the current study is shown in Figure 1a, with the outer lateral boundary of domain 2 excluded. Gravity wave activities over the two regions of the TP are of interest: one region is the main TP with topography height greater than $4.5 \mathrm{~km}$ (surrounded by a red line in Figure 1a), and the other region is the south slope of the TP with topographic height between $4.5 \mathrm{~km}$ and $0.3 \mathrm{~km}$ (the region between the red and blue lines within $26^{\circ} \mathrm{N}-35^{\circ} \mathrm{N}$ and $76^{\circ} \mathrm{E}-100^{\circ} \mathrm{E}$ in Figure 1a).

Based on the conclusions of He et al. [44], the biases between the 12-h forecast results of WRF-EnKF regional reanalysis data and observation are $0 \sim 0.15 \mathrm{~g} / \mathrm{Kg}$ in specific humidity, $-0.1 \sim 0.05^{\circ} \mathrm{C}$ in temperature, $-0.7 \sim 0.5 \mathrm{~m} / \mathrm{s}$ in zonal wind, $-0.1 \sim 1.5 \mathrm{~m} / \mathrm{s}$ in meridional wind, and less than $0.15 \mathrm{~mm} / \mathrm{h}$ in precipitation. This indicates that the 12-h WRF-EnKF forecast results perform well on the reproduction of meteorological fields.

\subsection{Spin-Up Time}

Aside from the direct comparison of meteorological fields with observations described in He et al. [44], in numerical simulation of gravity wave, model spin-up time (a pre-forecast period) should be long enough to allow gravity waves to develop and propagate vertically into upper levels. Plougonven et al. [49] adopted a $24 \mathrm{~h}$ spin-up time for the 20-km WRF model simulation of mountain waves above Antarctica. The 30-km MM5 model (PSU/NCAR mesoscale model [50]) simulation in Zhang et al. [51] indicated that $30 \mathrm{~h}$ of lead time was needed for jet-front and mountain waves. The 15-km $(3-\mathrm{km}, 1-\mathrm{km})$ WRF model simulation for a case study of midlatitude convective waves allows for $9 \mathrm{~h}$ of spin-up time in Stephan and Alexander [52]. The 2-km idealized WRF model simulation for gravity waves excited by meso-scale rainfall allows for $1 \mathrm{~h}$ of spin-up time in Stephan and Alexander [46].

Since the longest available forecast time in the current dataset is $12 \mathrm{~h}$, the spin-up time is examined by comparing momentum fluxes between the 6-h forecast results and the 12-h forecast results. Figure $1 b, c$ shows the area-averaged and 3-month averaged momentum fluxes varying with height. The tendency of momentum flux per unit volume varying with height is similar between those two different lead time forecasts. The maximum biases between them in the troposphere are $0.0087 \mathrm{~Pa}$ over the main TP and 0.0178 Pa over the south slope (Figure 1b), which implies that the 12-h forecast can allow more gravity wave development in the troposphere. The maximum increase from a 6-h 
forecast to a 12 -h forecast in stratosphere is a $15 \%$ increase over the main TP and a $25 \%$ increase over the south slope, which implies that the 12 -h forecast can ensure that more gravity waves with smaller vertical group velocities can have time to reach stratosphere.

\section{Background Field}

\subsection{Large-Scale Environment}

Figure 2a shows the 3-month mean of $500 \mathrm{hPa}$ geopotential height and $200 \mathrm{hPa}$ jet stream winds. The Tibetan Plateau is on the south side of the $200 \mathrm{hPa}$ jet and is on the southeast side of a weak south Asia subtropical high at $500 \mathrm{hPa}$. A shallow trough at $500 \mathrm{hPa}$ is over the main TP.
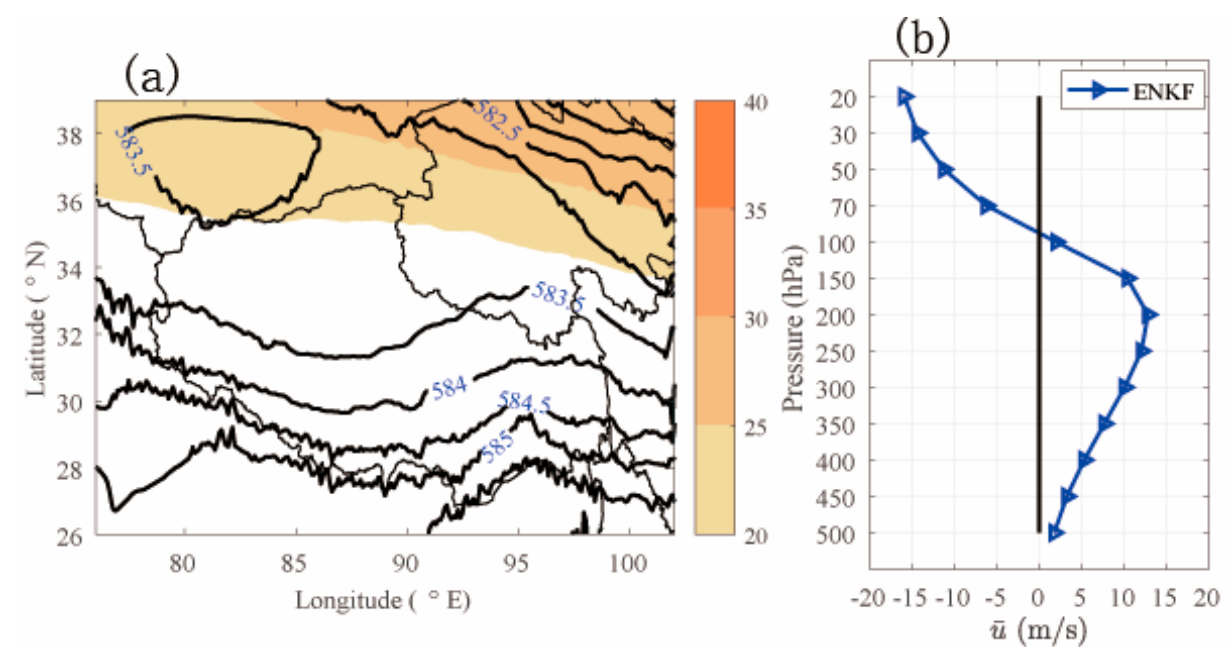

Figure 2. (a) Zonal wind speed at $200 \mathrm{hPa}$ (shading: greater than $20 \mathrm{~m} / \mathrm{s}$; contour interval is $5 \mathrm{~m} / \mathrm{s}$ ) and geopotential height at $500 \mathrm{hPa}$ (thick black lines). (b) Area and 3-month-averaged zonal wind (blue triangle line) varying with height.

The area-averaged and 3-month-averaged zonal wind, varying with height, is shown in Figure $2 b$. The mean zonal wind shifts direction between troposphere and stratosphere. The approximate zero wind levels are between $100 \mathrm{hPa}$ and $70 \mathrm{hPa}$. Since the phase speed of a stationary mountain wave is zero, most of the mountain waves should break at the stagnant critical level $(u=0)$ and will not propagate upward into the stratosphere.

\subsection{Diurnal Precipitation}

The 3-month-averaged diurnal cycle of 6-h accumulated rainfall starting at 06 UTC (12 local time) is shown in Figure 3. The local precipitation starts along the foot of south TP slope before the local noontime (Figure 3a). The main precipitation becomes active above the south slope of the TP in the late afternoon (18 local time, Figure $3 \mathrm{~b}$ ). The largest rainfall peak is next to the south edge of the main TP between $83^{\circ}$ and $90^{\circ} \mathrm{E}$. At midnight (Figure 3c), the precipitation is still active and prevails throughout the south TP slope, with a decay of rainfall in the west and development of a secondary rainfall maximum over the southeast slope. During the early morning, the rainfall diminishes and retreats to the foot of the south TP slope (Figure 3d). 
(a) 06 UTC

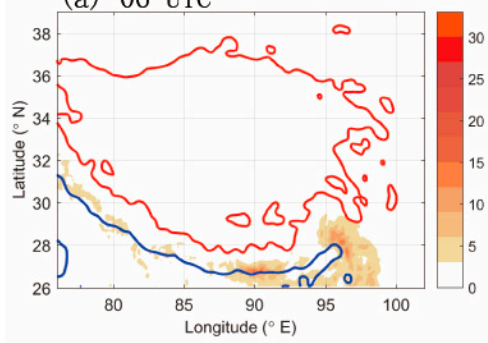

(c) 18 UTC

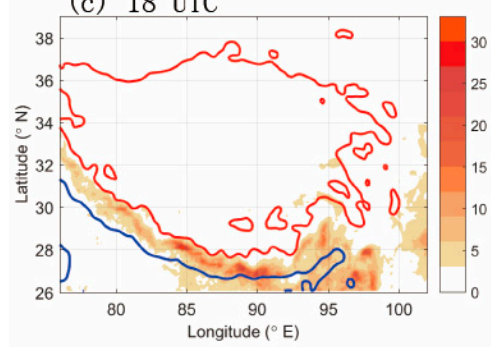

(b) 12 UTC

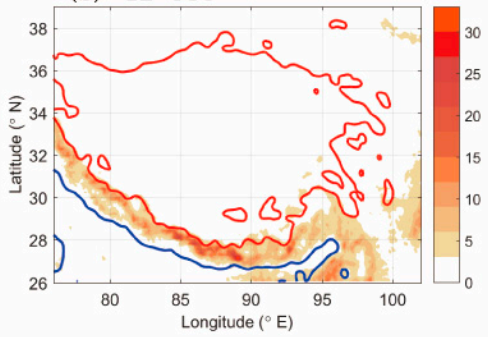

(d) 00 UTC

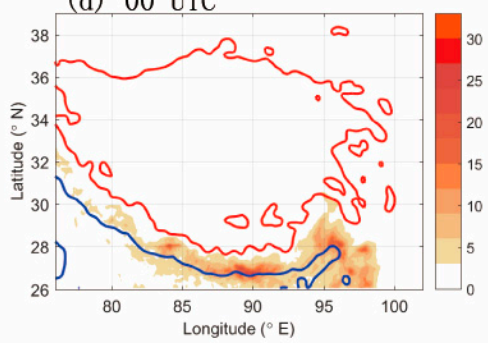

Figure 3. 6-h accumulated rainfall (shading: shaded region shows rainfall greater than $3 \mathrm{~mm} / 6 \mathrm{~h}$; contour interval is $3 \mathrm{~mm} / 6 \mathrm{~h}$ ) averaged over the 3-month period at (a) $06 \mathrm{UTC}$, (b) 12 UTC, (c) 18 UTC, and (d) 00 UTC. Local time is UTC time plus $6 \mathrm{~h}$.

Note that convection is frequently recorded over the east part of the main TP in summer. However, the intensity and duration of the rainfall are very poor, which induces the weak average value in Figure 3.

\section{Momentum Flux of Gravity Wave}

\subsection{Diurnal Variation of Momentum Flux}

In this section, the characteristics of gravity wave momentum fluxes above the TP region are examined. Here, we calculate the momentum fluxes for the gravity wave with horizontal wavelengths of 10-500 km. Note that gravity waves with horizontal wavelength less than $50 \mathrm{~km}$ are partially resolved due to the limit of horizontal grid spacing. Gravity waves with horizontal wavelength greater than $50 \mathrm{~km}$ are fully resolved. To avoid the underestimation of total momentum fluxes due to the opposite propagating directions [53], and to consider the density effects on the momentum amplitude [54], we calculated absolute horizontal momentum flux per unit volume $\sqrt{\left(\bar{\rho} \overline{\mathbf{u}^{\prime} w^{\prime}}\right)^{2}+\left(\bar{\rho} \overline{v^{\prime} w^{\prime}}\right)^{2}}$.

The diurnal variation in momentum flux per unit volume at $30 \mathrm{hPa}$ is shown in Figure 4 . At noontime (Figure 4a), the momentum fluxes are weakest. In late afternoon (Figure $4 \mathrm{~b}$ ), the momentum fluxes grow in both strength and areal coverage above the south slope of TP, with one peak between $85^{\circ}$ and $100^{\circ} \mathrm{E}$ and another peak on the west at $80^{\circ} \mathrm{E}$. The strongest momentum fluxes above the slope are enhanced between 85 and $100^{\circ} \mathrm{E}$ and the west peak decays at midnight (Figure $4 \mathrm{c}$ ). In the early morning, the momentum fluxes dissipate remarkably (Figure 4d). Throughout a 1-day cycle, the most active momentum fluxes have a similar geographic distribution to that of rainfall (Figure 3). The coincident distribution implies that the strong momentum fluxes over the south slope are tightly associated with rainfall.

Figure 5a shows the area-averaged absolute horizontal momentum flux per unit volume varying with height at different times and over the two regions. Figure $5 b$ shows the same quantity but in common logarithm scale (base 10) for better representation of the fluxes at higher altitude. In general, the area-averaged momentum flux per unit volume over the south slope of the TP (blue lines) is stronger than the corresponding one over the main TP (red lines). The amplitude of momentum fluxes decreases with height, and the strongest decrease appears between $150 \mathrm{hPa}$ and $70 \mathrm{hPa}$ (Figure 5b). This implies that the strongest wave-induced stress forcing occurs between $150 \mathrm{hPa}$ and $70 \mathrm{hPa}$, which 
is roughly the height of the stagnant layer $(70-100 \mathrm{hPa})$ in Figure $2 \mathrm{~b}$. This is also the region with the largest wave dissipation. Figure $5 \mathrm{a}, \mathrm{b}$ also shows a quantitative diurnal variation in momentum fluxes. The strongest value in the troposphere occurs at 12 UTC, while the strongest value in the lower stratosphere appears at both 12 and 18 UTC.

(a) 06 UTC

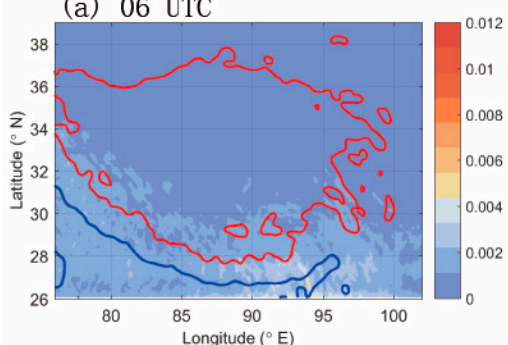

(c) 18 UTC

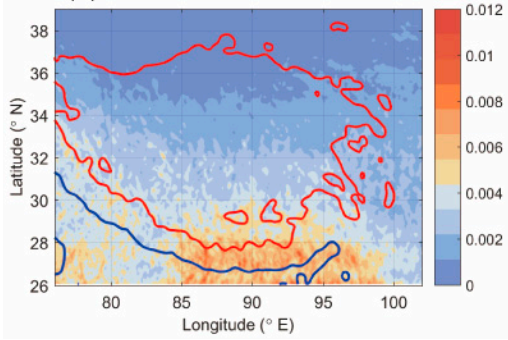

(b) 12 UTC

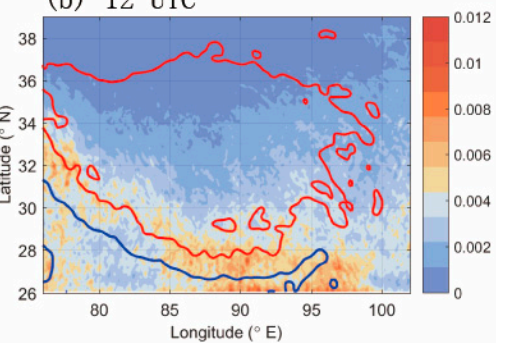

(d) 00 UTC

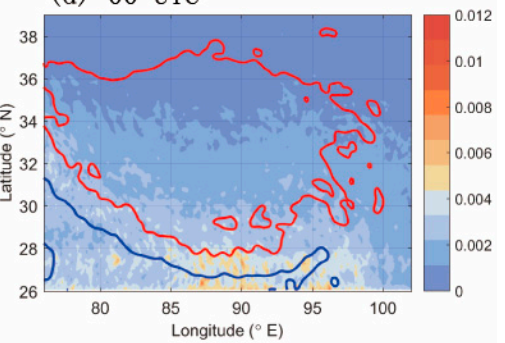

Figure 4. Geographic distribution of absolute horizontal momentum flux per unit volume (unit: Pa; shading, contour interval is $0.00109 \mathrm{~Pa}$ ) at $30 \mathrm{hPa}$ for 12 -h forecast results at (a) 06 UTC (12 LT), (b) 12 UTC (18 LT), (c) 18 UTC (00 LT), and (d) 00 UTC (06 LT). The horizontal wavelength is taken from $10 \mathrm{~km}$ to $500 \mathrm{~km}$. The red line represents the topography height at $4.5 \mathrm{~km}$. The blue line represents the topography height at $0.3 \mathrm{~km}$.
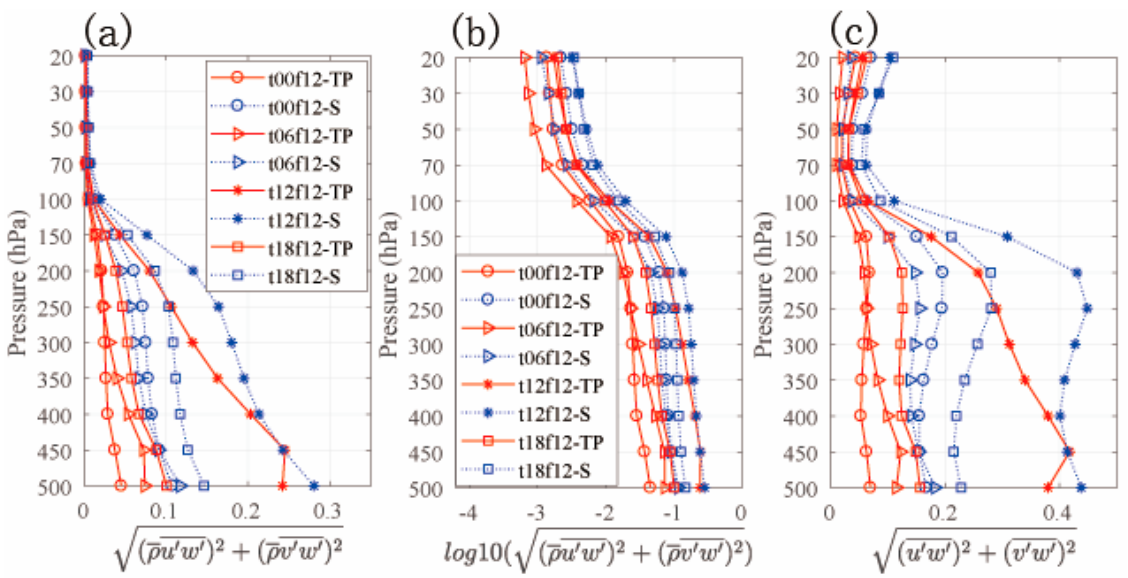

Figure 5. Diurnal variation of (a) area-averaged momentum fluxes per unit volume (unit: $\mathrm{Pa}$ ), (b) common logarithm (base 10) of area-averaged momentum fluxes per unit volume (unit: Pa) and (c) area-averaged momentum fluxes per unit mass (unit: $\mathrm{J} / \mathrm{kg}$ ) varying with height at $00 \mathrm{UTC}$ (circle), 06 UTC (triangle), 12 UTC (star) and 18 UTC (square) above the main TP (red solid line) and south slope of TP (blue dotted lines). Legends are abbreviations of simulation information. For example, f06 (12) refers to 6(12)-h forecast. t00 $(06,12,18)$ refers to UTC time. TP refers to the main TP region and S refers to the south slope of the TP.

If we ignore the density effects and only consider the wave amplitude, Figure $5 c$ displays the area-averaged horizontal momentum fluxes per unit mass in the vertical profile. Above the south slope of TP (blue lines), the abrupt growth in momentum flux intensity from the middle troposphere 
$(350 \mathrm{hPa}$ ) is likely tied to the gravity wave emitted from the top of cumulus cloud (Figure 3). Diurnal variation in momentum fluxes per unit mass also corresponds to rainfall.

\subsection{Power Spectrum of Momentum Flux}

The diurnal variation in the power spectrum of zonal momentum fluxes per unit volume at $30 \mathrm{hPa}$ is shown in Figure 6. The distribution of zonal momentum flux $\left(\bar{\rho} \overline{u^{\prime} w^{\prime}}\right)$ in the two-dimensional (kx, $\mathrm{ky})$ wavenumber space is dominated by the eastward momentum fluxes between $-45^{\circ}$ and $45^{\circ}$. The power spectrum of the meso-scale wave is weakest at 06 UTC (Figure 6a). At 12 UTC (Figure 6b) the corresponding power spectrum of the meso-scale wave becomes stronger, especially for the wave with a wavelength shorter than $400 \mathrm{~km}$. At 18 UTC (Figure 6c), the largest increase occurs for the wave with a wavelength of 100-400 km. At 00 UTC (Figure 6d), all the meso-scale gravity waves begin to decay. The time evolution of the power spectra implies that both the small-scale (10-200 km) convectively forced gravity waves and the other meso-scale $(200-500 \mathrm{~km})$ systems-forced gravity waves play an important role in diurnal variation.
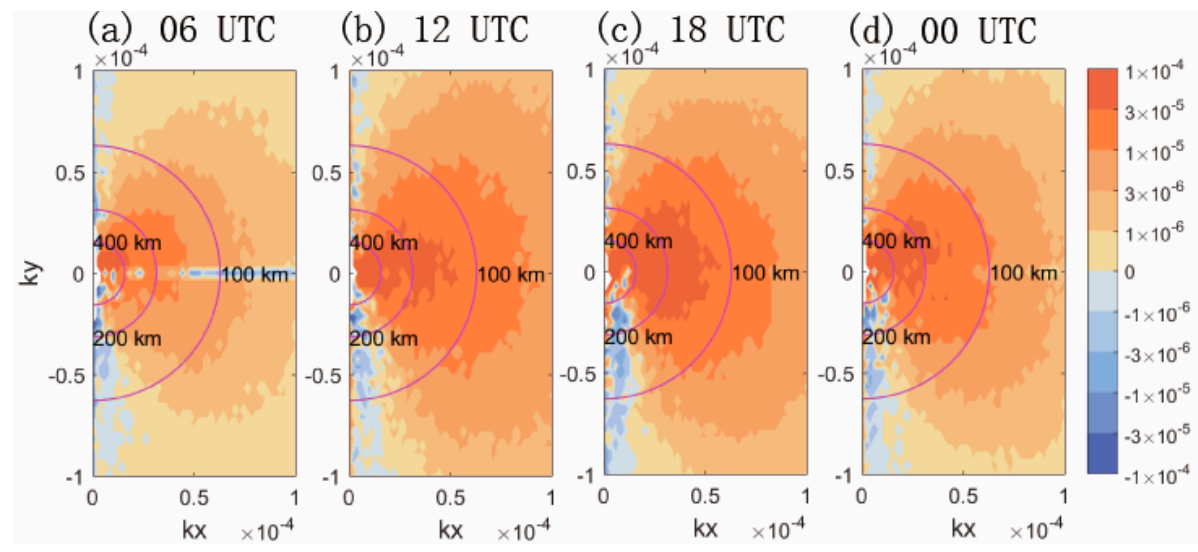

Figure 6. Time-averaged zonal momentum flux power spectra at $30 \mathrm{hPa}$ in horizontal (kx, ky) wavenumber space for 12-h forecast results at (a) 06 UTC, (b) 12 UTC, (c) 18 UTC and (d) 00 UTC.

The power spectra of meridional momentum fluxes per unit volume at $30 \mathrm{hPa}$ are shown at different times in Figure 7. The distribution of meridional momentum flux $\left(\bar{\rho} \overline{v^{\prime} w^{\prime}}\right)$ in the two-dimensional $(\mathrm{kx}$, ky) wavenumber space exhibits different patterns between the $k x \times k y>0$ sector and the $k y \times k y<0$ sector. Northward momentum flux is dominated in space with $k x \times k y>0$. The main propagating direction is between $30^{\circ}$ and $60^{\circ}$. Southward momentum flux is dominant in space with $\mathrm{kx} \times \mathrm{ky}<0$. The main propagating direction is between $-30^{\circ}$ and $-60^{\circ}$.

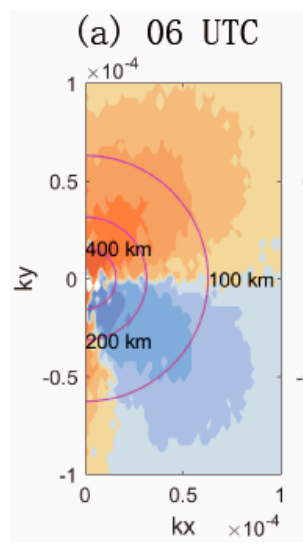

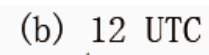

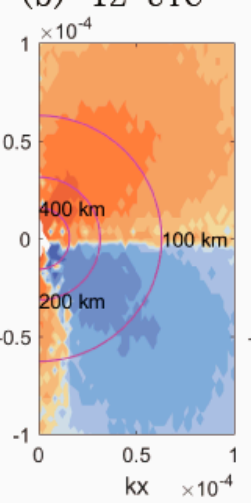

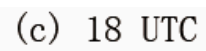

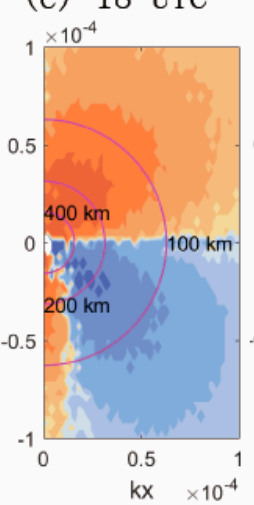

(d) 00 UTC

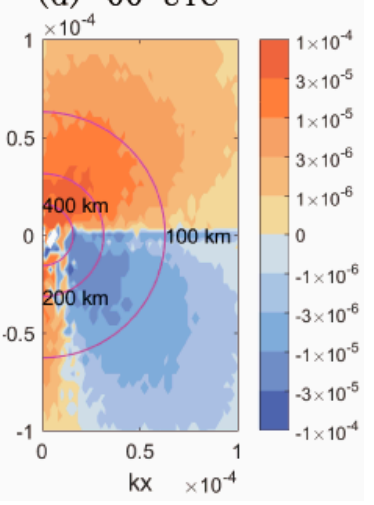

Figure 7. Time-averaged meridional momentum flux power spectra at $30 \mathrm{hPa}$ in horizontal (kx, ky) wavenumber space for 12-h forecast results at (a) 06 UTC, (b) 12 UTC, (c) 18 UTC and (d) 00 UTC. 
The diurnal variation in the intensity of meridional momentum fluxes is similar to that of zonal momentum fluxes. The power spectrum of meso-scale wave is weakest at noontime (Figure 7a) and strongest at midnight (Figure 7c). The intensity increase in meso-scale momentum fluxes occurs from late afternoon (Figure 7b) to midnight (Figure 7c). The intensity of northward momentum fluxes grows faster than that of southward momentum fluxes, especially for the wave with horizontal wavelength over $100 \mathrm{~km}$. The intensity reduction in the momentum fluxes begins in the early morning (Figure $7 \mathrm{~d}$ ).

Quantitative analyses of the power spectrum varying with horizontal wavelength at $30 \mathrm{hPa}$ are shown in Figure 8. For zonal momentum fluxes (Figure 8a), the strongest power curves happen at 12 UTC and 18 UTC. The power spectrum of the meso-scale wave increases fast for the wave with a wavelength of $70-500 \mathrm{~km}$. In detail, the gravity waves with shorter wavelengths $(70-200 \mathrm{~km})$ are more active in late afternoon (12 UTC). Such small-size waves could be excited by convection [55]. Waves with longer horizontal wavelengths (greater than $200 \mathrm{~km}$ and less than $500 \mathrm{~km}$ ) are strongest at midnight (18 UTC). This implies that the energy contributed by meso-scale atmospheric processes becomes strongest at 18 UTC. The weakest power curve is at noontime (06 UTC).
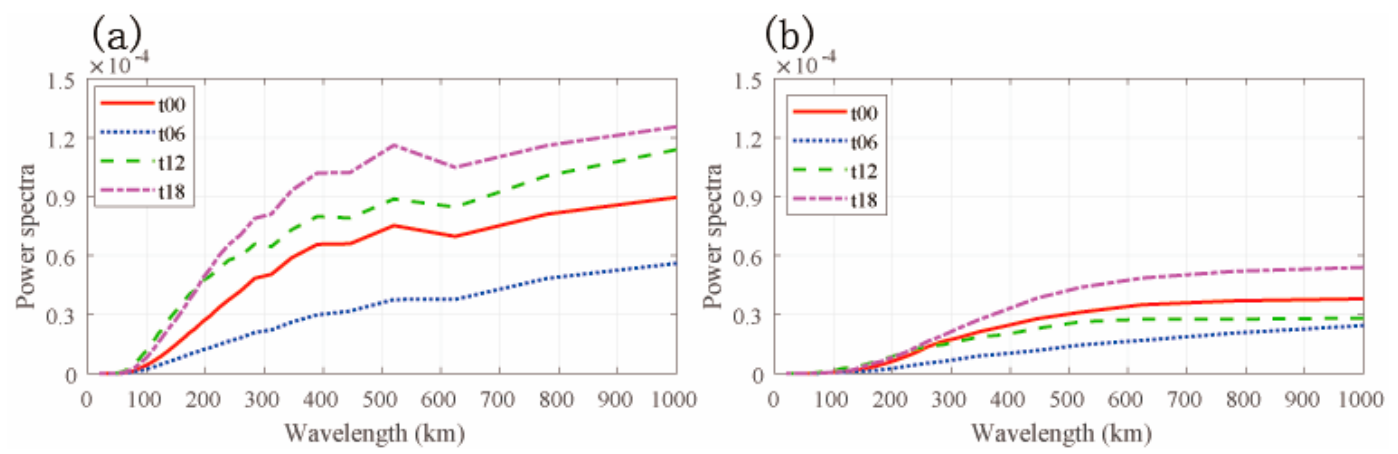

Figure 8. Power spectrum of (a) zonal and (b) meridional momentum fluxes per unit volume varying with wavelength at $30 \mathrm{hPa}$ and at different times in a 1-day cycle.

For meridional momentum fluxes (Figure $8 \mathbf{b}$ ), the offset of positives and negatives leads to a small positive net, which confirms that the northward momentum fluxes are stronger than the southward fluxes, as described in Figure 7. Small-scale meridional momentum fluxes are maximum in late afternoon (12 UTC), while meso-scale meridional momentum fluxes are maximum at midnight (18 UTC). The meridional momentum fluxes in early morning (00 UTC) is larger than the corresponding fluxes at noontime (06 UTC).

\section{Gravity Wave Energy in Lower Stratosphere}

Gravity wave kinetic energy $\frac{1}{2}\left(\overline{u^{\prime 2}}+\overline{v^{\prime 2}}\right)(\mathrm{KE})$, potential energy $\frac{1}{2} \frac{g^{2}}{N^{2}} \overline{\left(\frac{T^{\prime}}{T}\right)^{2}}$ (PE) and vertical fluctuation energy $\frac{1}{2} \overline{w^{\prime 2}}(\mathrm{VE})$ were used as indicators of gravity waves in previous climatology studies $[9,10]$. In this section, the diurnal variations of the three gravity wave energies are briefly explored.

The first column of Figure 9 illustrates the diurnal cycle of $\mathrm{KE}$ at $30 \mathrm{hPa}$ (Figure 9a1-a4). On spatial distribution, KE exhibits a latitudinal trend with a maximum around $27^{\circ}-28^{\circ} \mathrm{N}$. The spatial and temporal distribution of maximum KE matches the main rainfall peak along the south slope of TP between $85^{\circ} \mathrm{E}$ and $95^{\circ} \mathrm{E}$ (Figure 3). In a 1-day cycle, the strongest KE occurs at $18 \mathrm{UTC}$.

The time evolution of $\mathrm{PE}$ at $30 \mathrm{hPa}$ is shown in the second column (Figure 9b1-b4). The weakest PE occurs at 06 UTC (Figure 9b1) and the strongest PE occurs at 18 UTC (Figure 9b3). PE exhibits the flake distribution. From 12 UTC to 00 UTC, the strong PE extends from the south part of the TP to the south side of the TP. The PE peak also matches the main rainfall peak between $85^{\circ} \mathrm{E}$ and $95^{\circ} \mathrm{E}$ (Figure 3). 

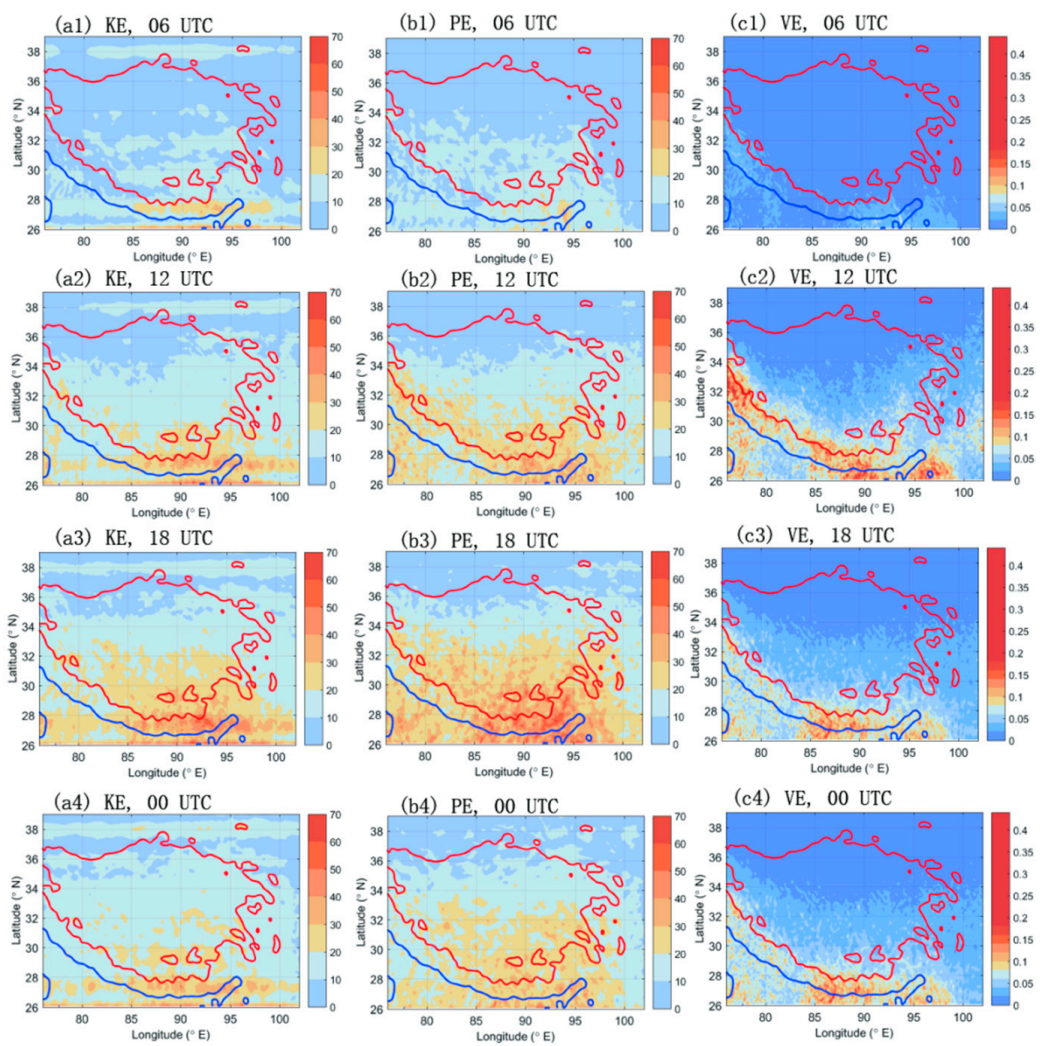

Figure 9. Time-averaged (a1-a4) KE (unit: J/kg, shading, c.i. = 10), (b1-b4) PE (unit: J/kg, shading, c.i. = 10), and (c1-c4) VE (unit: $\mathrm{J} / \mathrm{kg}$, shading, c.i. = 0.02; due to the large amplitude oscillation at different times, same red color uses for VE value greater than 0.2) at (a1-c1) 06 UTC, (a2-c2) 12 UTC, (a3-c3) 18 UTC, and (a4-c4) 00 UTC at $30 \mathrm{hPa}$.

The vertical fluctuation energy (VE) variation in a 1-day cycle is shown in the final column of Figure 9. The order of VE amplitude is much smaller than that of PE and KE. However, its coverage and diurnal variation are highly tied to the convection in details. Especially at 12 UTC (Figure 9c2), there are three VE peaks, located individually over the south slope, west to $80^{\circ} \mathrm{E}$ and between $85^{\circ}$ and $100^{\circ} \mathrm{E}$. This confirms that the convection-forced gravity wave can transport into the stratosphere. VE in the stratosphere is an effective indicator of convectively generated gravity waves above the south slope of the TP.

\section{Conclusions and Discussion}

The features of gravity waves in the lower stratosphere over the Tibetan Plateau in 2015 summer were examined by using high-resolution $(10 \mathrm{~km})$ downscaled simulations from WRF-EnKF regional reanalysis data. The focus is put on the diurnal variation in gravity wave momentum fluxes and wave energies.

Convection is proposed to be an important wave source over the TP in summer. Diurnal precipitation is active above the south slope of the TP with the strongest value persisting from late afternoon (12 UTC) to midnight (18 UTC). The spatial and temporal distributions of the momentum fluxes of gravity waves with $10-500 \mathrm{~km}$ horizontal wavelengths match the rainfall variation. This implies that convection and the associated meso-scale atmospheric processes largely contribute to the active gravity waves.

The power spectra of momentum fluxes show that small-scale gravity waves with wavelengths shorter than $200 \mathrm{~km}$ are active in the late afternoon (12 UTC), and meso-scale gravity waves with wavelengths of 200 500 km are active at midnight (18 UTC). The distribution of zonal momentum fluxes $\left(\bar{\rho} \overline{u^{\prime} w^{\prime}}\right)$ in the two-dimensional $(\mathrm{kx}, \mathrm{ky})$ wavenumber space is dominated by the eastward momentum 
fluxes between $-45^{\circ}$ and $45^{\circ}$. Both northward and southward momentum fluxes are apparent in meridional momentum fluxes $\left(\bar{\rho} \overline{v^{\prime} w^{\prime}}\right)$. However, northward momentum flux is relatively larger.

The kinetic, potential and vertical fluctuation energies of gravity waves with 10-500 km wavelengths are also examined in the lower stratosphere. All three energies exhibit an increase in rainfall area. However, the main structures of those three energies are different. KE displays a latitudinal tendency. PE exhibits a flake distribution from the south part of the TP to the south side of the TP. VE distribution and variation agree well with the diurnal rainfall. VE in the lower stratosphere acts like an effective indicator of convectively generated gravity waves.

It should be kept in mind that the above conclusions are based on simulations with relatively short spin-up times for gravity waves. In order to include more gravity waves with smaller vertical group velocities, simulations with longer lead times should be considered in the future. In addition, future work will attempt to perform gravity-wave ray-tracing experiments [56], as well as sensitivity experiments with respect to diabatic heating [28] and topography [57], in order to further verify the current results on wave source mechanisms and propagating wave characteristics. With all these inadequacies aside, the promising and encouraging findings of this study provide considerable motivation for our next steps on this research topic.

Author Contributions: Conceptualization, T.Q. and F.Z.; methodology, T.Q. and J.W. and Y.L.; software, T.Q.; validation, T.Q. and J.W.; formal analysis, T.Q. and J.W.; investigation, T.Q. and J.W.; resources, T.Q.; data curation, J.H.; writing - original draft preparation, T.Q.; writing—review and editing, T.Q., J.W., Y.L. and J.H.; visualization, T.Q.; supervision, T.Q. and J.W.; project administration, T.Q. and F.Z.; funding acquisition, T.Q., J.W. and F.Z. All authors have read and agreed to the published version of the manuscript.

Funding: This research was funded by the CN National Research and Development Projects, grant number 2018YFC1505705; the Basic Research Fund of the Chinese Academy of Meteorological Sciences, grant number 2019Z008; and the US National Science Foundation, grant numbers AGS-1305798 and 1712290.

Acknowledgments: Thanks to three anonymous reviewers for their helpful comments. The WRF model developed by NCAR was employed. Computing was performed at the Texas Advanced Computer Center. Comments from Craig C. Epifanio were beneficial.

Conflicts of Interest: The authors declare no conflict of interest.

\section{References}

1. McFarlane, N.A. The effect of orographically excited gravity wave drag on the general circulation of the lower stratosphere and troposphere. J. Atmos. Sci. 1987, 44, 1775-1800. [CrossRef]

2. Epifanio, C.C.; Qian, T. Wave-Turbulence Interactions in a breaking mountain wave. J. Atmos. Sci. 2008, 65, 3139-3158. [CrossRef]

3. Lindzen, R.S. Turbulence and stress owing to gravity wave and tidal break down. J. Geophys. Res. 1981, 86, 9707-9714. [CrossRef]

4. Holton, J.R. The role of gravity wave induced drag and diffusion in the momentum budget of the mesosphere. J. Atmos. Sci. 1982, 39, 791-799. [CrossRef]

5. Holton, J.R. The influence of gravity wave breaking on the general circulation of the middle atmosphere. J. Atmos. Sci. 1983, 40, 2497-2507. [CrossRef]

6. Vincent, R.A.; Reid, I.M. Hf Doppler measurements of mesospheric momentum fluxes. J. Atmos. Sci. 1983, 40, 1321-1333. [CrossRef]

7. Wang, L.; Geller, M.A. Morphology of gravity-wave energy as observed from 4 years (1998-2001) of high vertical resolution U.S. radiosonde data. J. Geophys. Res. 2003, 108, 4489. [CrossRef]

8. Wang, L.; Geller, M.A.; Alexander, M.J. Spatial and temporal variations of gravity wave parameters. Part I: Intrinsic frequency, wavelength, and vertical propagation direction. J. Atmos. Sci. 2005, 62, 125-142. [CrossRef]

9. Geller, M.A.; Gong, J. Gravity wave kinetic, potential, and vertical fluctuation energies as indicators of different frequency gravity waves. J. Geophys. Res. 2010, 115. [CrossRef]

10. Gong, J.; Geller, M.A. Vertical fluctuation energy in United States high vertical resolution radiosonde data as an indicator of convective gravity wave sources. J. Geophys. Res. 2010, 115. [CrossRef] 
11. Baldwin, M.P.; Gray, L.J.; Dunkerton, T.J.; Hamilton, K.; Haynes, P.H.; Randel, W.J.; Holton, J.R.; Alexander, M.J.; Hirota, I.; Horinouchi, T.; et al. The quasi-biennial oscillation. Rev. Geophys. 2001, 39, 179-230. [CrossRef]

12. Shu, J.C.; Tian, W.; Hu, D.; Zhang, J.; Shang, L.; Tian, H.; Xie, F. Effects of the quasi-biennial oscillation and stratospheric semiannual oscillation on tracer transport in the upper stratosphere. J. Atmos. Sci. 2013, 70, 1370-1389. [CrossRef]

13. Smith, R.B. Linear theory of stratified hydrostatic flow past an isolated mountain. Tellus 1980, 32, 348-364. [CrossRef]

14. Durran, D.R. Mesoscale Meteorology and Forecasting. In Mountain Waves; Ray, P.S., Ed.; American Meteorological Society: Boston, MA, USA, 1986; pp. 472-492.

15. Alexander, M.J.; Holton, J.R.; Durran, D.R. The gravity wave response above deep convection in as quall line simulation. J. Atmos. Sci. 1995, 52, 2212-2226. [CrossRef]

16. Alexander, M.J.; Pfister, L. Gravity wave momentum flux in the lower stratosphere over convection. Geophys. Res. Lett. 1995, 22, 2029-2032. [CrossRef]

17. Lane, T.P.; Reeder, M.J.; Clark, T.L. Numerical modeling of gravity wave generation by deep tropical convection. J. Atmos. Sci. 2001, 58, 1249-1274. [CrossRef]

18. Rotunno, R. On the linear theory of the land and sea breeze. J. Atmos. Sci. 1983, 40, 1999-2009. [CrossRef]

19. Snyder, C.; Skamarock, W.C.; Rotunno, R. Frontal dynamics near and following frontal collapse. J. Atmos. Sci. 1993, 50, 3194-3211. [CrossRef]

20. Griffiths, M.; Reeder, M.J. Stratospheric inertia-gravity waves generated in a numerical model of frontogenesis. I: Model solutions. Q. J. R. Meteorol. Soc. 1996, 122, 1153-1174.

21. Qian, T.; Epifanio, C.C.; Zhang, F. Linear theory calculation for the sea breeze in a background wind: The equatorial case. J. Atmos. Sci. 2009, 66, 1749-1763. [CrossRef]

22. Qian, T.; Epifanio, C.C.; Zhang, F. Topographic effects on the tropical land and sea breeze. J. Atmos. Sci. 2012, 69, 130-149. [CrossRef]

23. Buhler, O.; McIntyre, M.E.; Scinocca, J.F. On shear-generated gravity waves that reach the mesosphere. Part I: Wave generation. J. Atmos. Sci. 1999, 56, 3749-3763. [CrossRef]

24. Buhler, O.; McIntyre, M.E. On shear-generated gravity waves that reach the mesosphere. Part II: Wave propagation. J. Atmos. Sci. 1999, 56, 3764-3773. [CrossRef]

25. Zhang, F. Generation of mesoscale gravity waves in upper-tropospheric jet-front systems. J. Atmos. Sci. 2004, 61, 440-457. [CrossRef]

26. Wang, S.; Zhang, F. Sensitivity of mesoscale gravity waves to the baroclinicity of jet-front systems. Mon. Weather Rev. 2007, 135, 670-688. [CrossRef]

27. Wang, S.; Zhang, F.; Snyder, C. Generation and propagation of inertial gravity waves from vortex dipoles and jets. J. Atmos. Sci. 2009, 66, 1294-1314. [CrossRef]

28. Wei, J.; Zhang, F. Mesoscale Gravity Waves in Moist Baroclinic Jet-Front Systems. J. Atmos. Sci. 2014, 71, 929-952. [CrossRef]

29. Wei, J.; Zhang, F.; Richter, J.H. An Analysis of Gravity Wave Spectral Characteristics in Moist Baroclinic Jet-Front Systems. J. Atmos. Sci. 2016, 73, 3133-3155. [CrossRef]

30. Bao, X.; Zhang, F.; Sun, J. Diurnal variations of warm-season precipitation east of the Tibetan Plateau over China. Mon. Weather Rev. 2011, 139, 2790-2810. [CrossRef]

31. Qian, T.; Zhao, P.; Zhang, F.; Bao, X. Rainy-season Precipitation over the Sichuan Basin and Adjacent Regions in Southwestern China. Mon. Weather Rev. 2015, 143, 382-394. [CrossRef]

32. Lin, Y.L.; Smith, R.B. Transient Dynamics of airflow near a local heat source. J. Atmos. Sci. 1986, 43, 40-49. [CrossRef]

33. Epifanio, C.C.; Durran, D.R. Three-dimensional effects in high-drag-state flows over long ridges. J. Atmos. Sci. 2001, 58, 1051-1065. [CrossRef]

34. Epifanio, C.C.; Rotunno, R. The dynamics of orographic wake formation in flows with upstream blocking. J. Atmos. Sci. 2005, 62, 3127-3150. [CrossRef]

35. Kitamura, Y.; Hirotal, I. Small-scale disturbances in the lower stratosphere revealed by daily rawin sonde observations. J. Meteorol. Soc. Jpn. 1989, 67, 817-830. [CrossRef]

36. Wu, D.L.; Zhang, F. A study of mesoscale gravity waves over the North Atlantic with satellite observations and a mesoscale model. J. Geophys. Res. 2004, 109. [CrossRef] 
37. Zhang, S.; Yi, F. Latitudinal and seasonal variations of inertial gravity wave activity in the low atmosphere over central China. J. Geophys. Res. 2007, 112. [CrossRef]

38. Alexander, M.J. Global and seasonal variations in three-dimensional gravity wave momentum flux from satellite limb-sounding temperatures. Geophys. Res. Lett. 2015, 42, 6860-6867. [CrossRef]

39. Hecht, J.H.; Fritts, D.C.; Wang, L.; Gelinas, L.J.; Rudy, R.J.; Walterscheid, R.L.; Taylor, M.J.; Pautet, P.D.; Smith, S.; Franke, S.J. Observations of the break down of mountain waves over the Andes lidar observatory at Cerro Pachonon 8/9 July 2012. J. Geophys. Res. 2018, 123, 276-299.

40. Jiang, Q.; Doyle, J.D.; Eckermann, S.D.; Willianms, B.P. Stratospheric trailing gravity waves from New Zealand. J. Atmos. Sci. 2019, 79, 1565-1586. [CrossRef]

41. Haynes, P. Stratospheric dynamics. Annu. Rev. Fluid Mech. 2005, 37, 263-293. [CrossRef]

42. Geller, M.A.; Alexander, M.J.; Love, P.T.; Bacmeister, J.; Ern, M.; Hertzog, A.; Manzini, E.; Preusse, P.; Sato, K.; Scaife, A.A.; et al. A comparison between gravity wave momentum fluxes in observations and climate models. J. Clim. 2013, 26, 6383-6405. [CrossRef]

43. Schirber, S.; Manzini, E.; Krismer, T.; Giorgetta, M. The quasi-oscillation in a warmer climate: Sensitivity to different gravity wave parameterizations. Clim. Dyn. 2015, 45, 825-836. [CrossRef]

44. He, J.; Zhang, F.; Chen, X.; Bao, X.; Chen, D.; Kim, H.M.; Lai, H.; Leung, L.R.; Ma, X.; Meng, Z.; et al. Development and evaluation of an Ensemble-based data assimilation system for regional reanalysis over the Tibetan Plateau and surrounding regions. J. Adv. Model. Earth Syst. 2019, 11, 2503-2522. [CrossRef] [PubMed]

45. WRF Model. Available online: https://www.mmm.ucar.edu/weather-research-and-forecasting-model (accessed on 11 June 2020).

46. Stephan, C.; Alexander, M.J. Realistic simulations of atmospheric gravity waves over the continental U.S. using precipitation radar data. J. Adv. Model. Earth Syst. 2015, 7, 823-835. [CrossRef]

47. Chen, X.; Pauluis, O.M.; Zhang, F. Regional simulation of Indian summer monsoon intraseasonal oscillations at gray-zone resolution. Atmos. Chem. Phys. Discuss. 2018, 18, 1003-1022. [CrossRef]

48. Klemp, J.B.; Wilhelmson, R.B. The simulation of three-dimensional convective storm dynamics. J. Atmos. Sci. 1978, 35, 1070-1096. [CrossRef]

49. Plougonven, R.; Arsac, A.; Hertzog, G.L.; Vial, F. Sensitivity study for mesoscale simulations of gravity waves above Antarctica during Vorcore. Q. J. R. Meteorol. Soc. 2010, 136, 1371-1377.

50. MM5 Model. Available online: http://www2.ucar.edu/mm5 (accessed on 11 June 2020).

51. Zhang, F.; Zhang, M.; Wei, J.; Wang, S. Month-long simulations of gravity waves over North America and North Atlantic in comparison with satellite observations. Acta Meteorol. Sin. 2013, 27, 446-454. [CrossRef]

52. Stephan, C.; Alexander, M.J. Summer season squall-line simulations: Sensitivity of gravity waves to physics parameterization and implications for their parameterization in global climate models. J. Atmos. Sci. 2014, 71, 3367-3391. [CrossRef]

53. Vincent, R.A.; Alexander, M.J.; Dolman, B.K.; MacKinnon, A.D.; May, P.T.; Kovalam, S.; Reid, I.M. Gravity wave generation by convection and momentum deposition in the mesosphere-lower thermosphere. J. Geophys. Res. Atmos. 2013, 118, 6233-6245. [CrossRef]

54. Wei, J.; Bölöni, G.; Achatz, U. Efficient modelling of the interaction of mesoscale gravity waves with unbalanced large-scale flows: Pseudomomentum-flux convergence versus direct approach. J. Atmos. Sci. 2019, 76, 2715-2738. [CrossRef]

55. Lane, T.P.; Reeder, M.J.; Guest, F.M. Convectively generated gravity waves observed from radiosonde data taken during MCTEX. Q. J. R. Meteorol. Soc. 2003, 129, 1731-1740. [CrossRef]

56. Wei, J.; Zhang, F. Tracking gravity waves in moist baroclinic jet-front systems. J. Adv. Model. Earth Syst. 2015, 7, 67-91. [CrossRef]

57. Zhang, F.; Koch, S.E.; Kaplan, M.L. Numerical simulations of a large-amplitude gravity wave event. Meteorol. Atmos. Phys. 2003, 84, 199-216. [CrossRef]

(C) 2020 by the authors. Licensee MDPI, Basel, Switzerland. This article is an open access article distributed under the terms and conditions of the Creative Commons Attribution (CC BY) license (http://creativecommons.org/licenses/by/4.0/). 